\title{
NOTE
}

\section{Decadal changes in adult size of salmon-eating killer whales in the eastern North Pacific}

\author{
Molly J. Groskreutz ${ }^{1,2}$, John W. Durban ${ }^{1, *}$, Holly Fearnbach ${ }^{2}$, \\ Lance G. Barrett-Lennard ${ }^{3}$, Jared R. Towers ${ }^{4}$, John K. B. Ford ${ }^{4}$ \\ ${ }^{1}$ Marine Mammal and Turtle Division, Southwest Fisheries Science Center, National Marine Fisheries Service, NOAA, \\ 8901 La Jolla Shores Drive, La Jolla, CA 92037, USA \\ ${ }^{2}$ SR3, SeaLife Response, Rehabilitation and Research, 2255 Harbor Avenue SW, Suite 101, Seattle, WA 98126, USA \\ ${ }^{3}$ Coastal Ocean Research Institute, PO Box 3232, Vancouver, BC V6B 3X8, Canada \\ ${ }^{4}$ Fisheries and Oceans Canada, Pacific Biological Station, Cetacean Research Program, 3190 Hammond Bay Road, Nanaimo, \\ BC V9T 6N7, Canada
}

\begin{abstract}
Two populations of killer whales aggregate around Vancouver Island to feed primarily on Chinook salmon. Aerial photogrammetry of endangered southern residents has documented some adults growing to smaller lengths in recent decades, suggesting that early growth may have been constrained by low Chinook availability in the 1990s. We investigated whether growth and adult length were also constrained in the more abundant northern residents. Photographs were collected from an unmanned hexacopter at altitudes of 30 to $37 \mathrm{~m}$ over $4 \mathrm{yr}, 2014$ to 2017. Images were linked to 78 individuals of known age and sex based on distinctive saddle patch pigmentation. The length of each whale was estimated by measuring pixel dimensions between both the snout and dorsal fin and the dorsal fin and fluke; these were scaled to real size using camera lens focal length and altitude, determined by a laser or pressure altimeter. Total length, derived by summing the longest (flattest) of each measure, ranged from $2.42 \mathrm{~m}$ for a firstyear calf to $7.45 \mathrm{~m}$ for the largest adult male. A Bayesian change point analysis revealed that adult whales $<40 \mathrm{yr}$ old were on average shorter by $0.44 \mathrm{~m}$ than older adults, which grew to typical lengths of 6.28 and $7.14 \mathrm{~m}$ for females and males, respectively. This mirrors the growth trends reported for southern residents, supporting demographic evidence of correlated prey limitation in both populations. The growth data suggest that the effects of nutritional stress are not only acutely lethal but also have long-term consequences for the condition of whales in both populations.
\end{abstract}

KEY WORDS: Photogrammetry $\cdot$ Drone $\cdot \mathrm{UAS} \cdot \mathrm{UAV} \cdot$ Growth $\cdot$ Nutrition $\cdot$ Orca

\section{INTRODUCTION}

Two populations of killer whales Orcinus orca frequent the waters around Vancouver Island to feed primarily on Chinook salmon Oncorhynchus tshawytscha returning to rivers off the west coast of Canada and the United States (Ford \& Ellis 2006). The southern resident killer whale (SRKW) population is

*Corresponding author: john.durban@noaa.gov listed as endangered by both countries (Fisheries and Oceans Canada 2008, National Marine Fisheries Service 2008) and currently numbers 75 individuals (K. Balcomb, Center for Whale Research, unpubl. data), while the northern resident killer whale (NKRW) population numbers around 300 individuals (Towers et al. 2015) and is listed as threatened in Canada (Fisheries and Oceans Canada 2008). Both popu-

(C) M.J.G., H.F., L.G.B.-L., J.R.T., Fisheries and Oceans Canada and, outside the USA, the US Government 2019. Open Access under Creative Commons by Attribution Licence. Use, distribution and reproduction are unrestricted. Authors and original publication must be credited. 
lations are hypothesized to be periodically food limited, with declines in coast-wide Chinook salmon (notably in the 1990s) coinciding with high mortality (Ford et al. 2010) and constrained reproduction (Ward et al. 2009) in both populations. However, despite these correlations, there is still uncertainty about if and when these whales are nutritionally stressed (Hilborn et al. 2012), which is constraining management recovery actions. For SRKWs, further evidence has come from aerial photogrammetry, which has documented declines in body condition of some whales (Fearnbach et al. 2018) and a trend for growth to smaller adult lengths in recent decades (Fearnbach et al. 2011). Fearnbach et al. (2011) hypothesized that this decline in adult length was likely the result of early growth being constrained by prey availability, but the sample size of older adults in the SRKW population was relatively small due to their low abundance. To investigate further, we used photogrammetry analyses of high-resolution photos to address the hypothesis that growth and adult length have also been constrained in the more abundant NRKWs.

\section{MATERIALS AND METHODS}

Aerial photographs of NRKWs were collected using an unmanned hexacopter launched from an $8.2 \mathrm{~m}$ boat (Durban et al. 2015) operating in the protected waters between Queen Charlotte Strait and Johnstone Strait, off northeastern Vancouver Island (Fig. 1). During a 3 wk field effort in August of each year from
2014 to 2017, vertical photographs of whales were collected from altitudes of 30 to $37 \mathrm{~m}$ using a micro $4 / 3$ camera with a $25 \mathrm{~mm}$ lens that provided undistorted images with a water level resolution of $<1.8 \mathrm{~cm}$ (Durban et al. 2015). We linked photographs to individual whales of known age and sex by matching distinctive saddle patch pigmentation in aerial images to a longterm boat-based photo-identification catalog (Durban et al. 2015, Towers et al. 2015; Fig. 2). Birth year was observed for 4 new calves born during the years of this study (Table 1) and reported in Towers et al. (2015) for all other whales. These were based on the first appearance of whales in the population census, except for whales born before 1973, for which birth years were estimated using techniques described in Olesiuk et al. (1990). Ages were standardized by assuming a February 1 birth date. Where known, sex for all whales was reported in Towers et al. (2015) and was classified as unknown for the 4 new calves.

Body measurements in pixels were scaled to real size for the majority of whales (all those imaged in 2017) using data from a laser altimeter, which has been shown to have a typical error of $\sim 0.1 \%$ (Dawson et al. 2017). For the remaining whales that were not imaged in 2017, scale was provided by a pressure altimeter with a typical error of $<1 \%$ (Durban et al. 2015). The length of each whale was estimated in the most recent year it was photographed by measuring pixel dimensions between both the snout and dorsal fin (SNDF) and the dorsal fin and fluke (DFFL; Fig. 2). Total length was derived for each whale by summing the longest (flattest) of each measure.

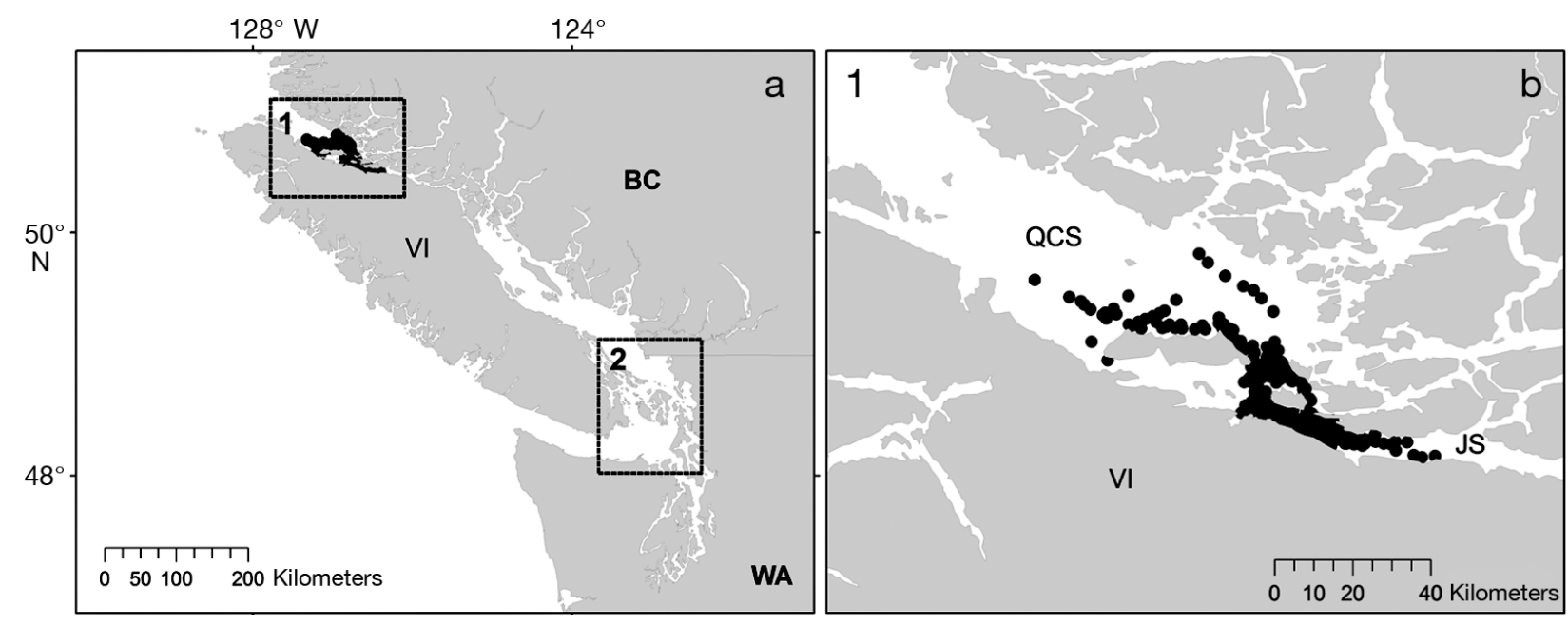

Fig. 1. Locations of 303 hexacopter flights used to collect vertical images of northern resident killer whales off the coast of British Columbia (BC), Canada. Rectangle 1 in (a) shows the location of the study area off northeastern Vancouver Island (VI) compared to the area between southern VI and Washington state (WA), USA, where comparative aerial images were collected from southern resident killer whales (rectangle 2; see Fearnbach et al. 2011). (b) shows a magnified view of rectangle 1, with flights (black dots: start locations) in the protected waters between Queen Charlotte Strait (QCS) and Johnstone Strait (JS) 


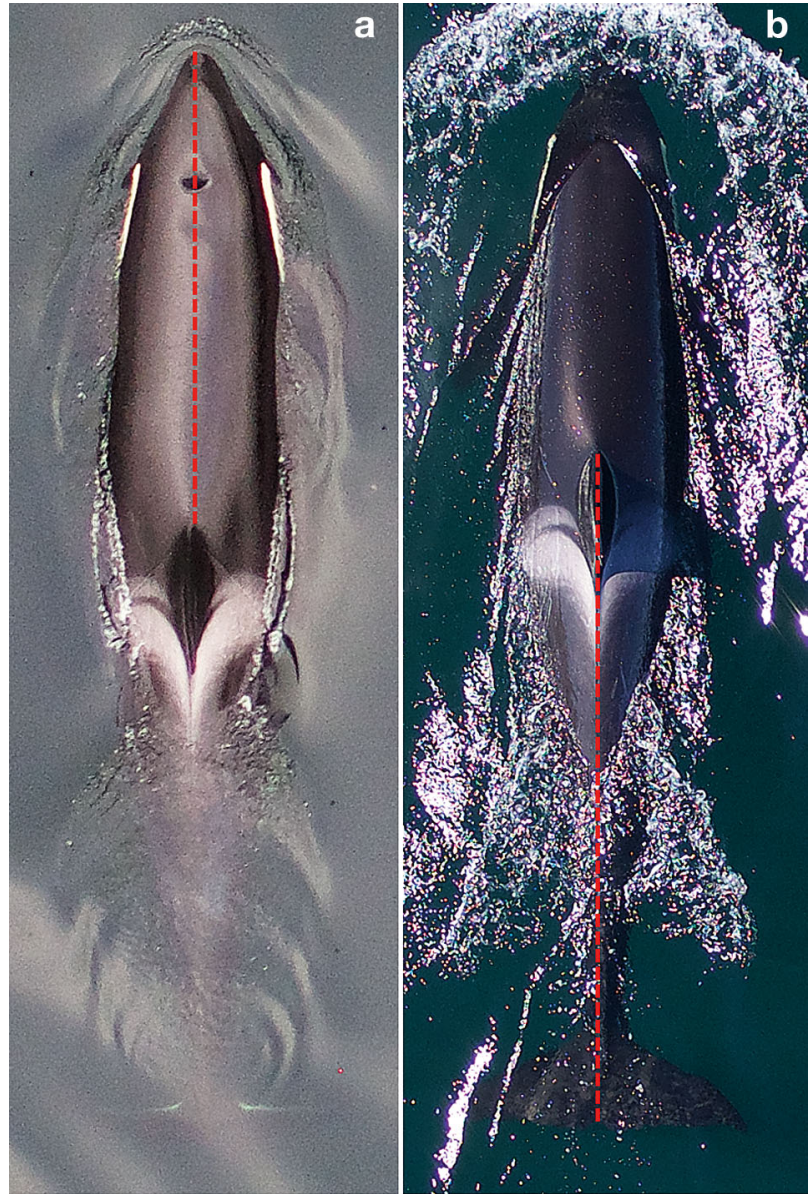

Fig. 2. Aerial images of the same adult female northern resident killer whale (A42) illustrating the 2 metrics of snout to dorsal fin (a) and dorsal fin to fluke (b) that were measured to derive total length. Also visible in both photos is the unique saddle patch pigmentation used to link measurements to individual whales of known age and sex (see Durban et al. 2015)

Trends in adult size were investigated by fitting a Bayesian change point model (Carlin et al. 1992) to length measurements for individuals of both sexes that were conservatively designated as adults by virtue of being $>20 \mathrm{yr}$ of age (Fearnbach et al. 2011). The total length (TL) measurements for each individual $j$ of each sex $i$ were assumed to be normally $(\mathrm{N})$ distributed, with a residual standard deviation $(\sigma)$ around a model $\mu$ that described 2 levels stratified by age:

$$
\begin{gathered}
\mathrm{TL}_{i j} \sim \mathrm{N}\left(\mu_{i j}, \sigma\right) \\
\mu_{i j}=\alpha_{i}+\beta \delta\left(\mathrm{age}_{i j}-c\right)
\end{gathered}
$$

where $\alpha$ represents the average length of adults of each sex before a change point at an unknown age $C_{\text {, }}$ to be estimated, and $\delta()$ represents a step function, defined as 1 if its argument was zero or positive and zero otherwise; therefore, $\beta$ describes the magnitude of a step change. We placed a flat uniform $\mathrm{U}(20,60)$ prior distribution on the timing of the change point and diffuse $\mathrm{N}(0,100)$ prior distributions on $\alpha_{i}$ and $\beta$ to let these be informed by the data. Similarly a $U(0,10)$ prior distribution was placed on $\sigma$.

We used WinBUGS software (Lunn et al. 2000) to implement Markov chain Monte Carlo (MCMC) sampling to estimate the posterior distribution for the unknown parameters, including the change point, after conditioning on the data.

To investigate if this change point model fit better than a simpler model with just a constant average adult size for each sex, we adopted the MCMC method of Carlin \& Chib (1995) for simultaneous model selection. A model indicator $k$ was included directly in the model, along with a parameter vector for each model: $\alpha^{1}$ and $\sigma^{1}$ for the constant model $\alpha^{2}$, $\beta, c$ and $\sigma^{2}$ for the change point model. We then sampled from this joint model space simultaneously, updating the model indicator $k$ at each iteration and then updating the parameters only for the model reflected by the current value of the model indicator. We assigned true priors for parameters when they were in the chosen model, and when they were not selected, we updated pseudo-priors that were precisely based on estimates of model parameters from separate pilot runs to facilitate switches between models. We set a discrete uniform prior distribution on the model indicator, to initially assign an equal probability of 0.5 to each model, and estimated the posterior probability $\mathrm{p}(k=2)$ of selecting the change point model. We based inference on 20000 MCMC iterations following an initial burn-in of 20000 iterations.

\section{RESULTS}

Images were collected during a total of 303 hexacopter flights, and analysis was constrained to 78 individuals with 3 or more measurements for each of the 2 body metrics (SNDF median images per whale $=14$; range: $3-40 ;$ DFFL median $=11$; range: $3-35$ ). This dataset comprised whales from 6 of 15 NRKW pods and 2 of 3 of the vocal clans (Table 1 ; see Towers et al. 2015). The majority of whales (67 of 78) imaged were associated with laser altimetry in 2017, with 6 additional individuals imaged using pressure altimetry in 2016, 2 in 2015, and 3 in 2014. TL estimates ranged from $2.42 \mathrm{~m}$ for a first-year calf to $7.45 \mathrm{~m}$ for the largest adult male (Table 1). 
Table 1. Length and age data by sex for 78 northern resident killer whales with $\geq 3$ photogrammetry measurements. Total length (TL) was derived by combining the flattest (max.) of the total number (n) snout to dorsal fin (SNDF) and dorsal fin to fluke (DFFL) measurements for each individual. Sex (F: female; M: male; U: unknown) and age from Towers et al. (2015), assuming a February 1 birth date

\begin{tabular}{|c|c|c|c|c|c|c|c|c|c|c|c|c|c|}
\hline $\begin{array}{l}\text { Whale } \\
\text { ID }\end{array}$ & $\begin{array}{l}\text { Birth } \\
\text { year }\end{array}$ & $\begin{array}{c}\text { Age } \\
\text { (yr) }\end{array}$ & Sex & $\begin{array}{c}\mathrm{n} \\
\text { SNDF }\end{array}$ & $\begin{array}{c}\mathrm{n} \\
\text { DFFL }\end{array}$ & $\begin{array}{c}\text { TL } \\
(\max .)\end{array}$ & $\begin{array}{l}\text { Whale } \\
\text { ID }\end{array}$ & $\begin{array}{l}\text { Birth } \\
\text { year }\end{array}$ & $\begin{array}{c}\text { Age } \\
\text { (yr) }\end{array}$ & Sex & $\begin{array}{c}\mathrm{n} \\
\text { SNDF }\end{array}$ & $\begin{array}{c}\mathrm{n} \\
\text { DFFL }\end{array}$ & $\begin{array}{c}\mathrm{TL} \\
\text { (max.) }\end{array}$ \\
\hline A69 & 1997 & 20.5 & $\mathrm{~F}$ & 21 & 15 & 5.79 & A103 & 2013 & 3.5 & $\mathrm{U}$ & 19 & 17 & 3.91 \\
\hline I63 & 1990 & 24.5 & $\mathrm{~F}$ & 11 & 11 & 5.60 & I145 & 2014 & 3.5 & $\mathrm{U}$ & 22 & 11 & 4.36 \\
\hline G51 & 1992 & 25.5 & $\mathrm{~F}$ & 13 & 7 & 5.77 & A108 & 2014 & 3.5 & $\mathrm{U}$ & 24 & 15 & 4.05 \\
\hline I68 & 1991 & 26.6 & $\mathrm{~F}$ & 11 & 13 & 5.97 & G105 & 2013 & 4.5 & $\mathrm{U}$ & 6 & 6 & 4.30 \\
\hline G48 & 1990 & 27.5 & $\mathrm{~F}$ & 7 & 3 & 5.74 & A106 & 2013 & 4.5 & $\mathrm{U}$ & 14 & 12 & 4.50 \\
\hline I65 & 1990 & 27.5 & $\mathrm{~F}$ & 25 & 21 & 6.24 & I137 & 2012 & 5.5 & $\mathrm{U}$ & 4 & 3 & 4.44 \\
\hline A54 & 1989 & 28.6 & $\mathrm{~F}$ & 16 & 15 & 5.78 & G104 & 2012 & 5.5 & $\mathrm{U}$ & 14 & 4 & 4.13 \\
\hline I51 & 1986 & 31.5 & $\mathrm{~F}$ & 21 & 18 & 6.21 & A101 & 2012 & 5.6 & $\mathrm{U}$ & 18 & 17 & 4.20 \\
\hline C13 & 1985 & 32.5 & $\mathrm{~F}$ & 9 & 9 & 5.77 & C30 & 2009 & 6.5 & $\mathrm{U}$ & 7 & 10 & 4.08 \\
\hline G37 & 1984 & 33.5 & $\mathrm{~F}$ & 14 & 15 & 5.92 & A99 & 2011 & 6.6 & $\mathrm{U}$ & 21 & 14 & 4.96 \\
\hline A50 & 1984 & 33.5 & $\mathrm{~F}$ & 18 & 17 & 5.77 & G93 & 2010 & 7.5 & $\mathrm{U}$ & 4 & 3 & 4.62 \\
\hline A43 & 1981 & 36.5 & $\mathrm{~F}$ & 21 & 21 & 5.60 & A95 & 2009 & 8.5 & $\mathrm{U}$ & 14 & 10 & 5.21 \\
\hline $\mathrm{A} 42$ & 1980 & 36.5 & $\mathrm{~F}$ & 19 & 16 & 5.82 & I128 & 2009 & 8.5 & $\mathrm{U}$ & 15 & 9 & 5.08 \\
\hline I4 & 1980 & 37.5 & $\mathrm{~F}$ & 15 & 9 & 6.06 & $\mathrm{C} 29$ & 2009 & 8.5 & $\mathrm{U}$ & 6 & 3 & 4.92 \\
\hline G22 & 1979 & 38.5 & $\mathrm{~F}$ & 21 & 11 & 5.93 & I129 & 2009 & 8.5 & $\mathrm{U}$ & 40 & 35 & 4.25 \\
\hline I35 & 1974 & 43.5 & $\mathrm{~F}$ & 13 & 9 & 6.49 & G92 & 2009 & 8.5 & $\mathrm{U}$ & 12 & 9 & 5.08 \\
\hline I13 & 1974 & 43.5 & $\mathrm{~F}$ & 4 & 8 & 6.22 & A88 & 2008 & 8.5 & $\mathrm{U}$ & 11 & 12 & 4.35 \\
\hline $\mathrm{I} 27$ & 1974 & 43.6 & $\mathrm{~F}$ & 21 & 18 & 5.86 & G86 & 2008 & 9.5 & $\mathrm{U}$ & 12 & 6 & 4.45 \\
\hline C10 & 1972 & 45.5 & $\mathrm{~F}$ & 15 & 13 & 6.28 & C28 & 2007 & 10.5 & $\mathrm{U}$ & 7 & 5 & 4.89 \\
\hline G20 & 1972 & 45.5 & $\mathrm{~F}$ & 8 & 7 & 6.14 & I1 22 & 2007 & 10.6 & $\mathrm{U}$ & 23 & 17 & 5.59 \\
\hline I16 & 1969 & 48.5 & $\mathrm{~F}$ & 32 & 23 & 6.51 & G81 & 2006 & 11.5 & $\mathrm{U}$ & 8 & 3 & 6.04 \\
\hline G3 & 1957 & 60.5 & $\mathrm{~F}$ & 17 & 16 & 6.23 & I103 & 2003 & 11.5 & $\mathrm{U}$ & 11 & 11 & 4.60 \\
\hline I76 & 1997 & 20.5 & M & 14 & 4 & 6.57 & G80 & 2006 & 11.5 & $\mathrm{U}$ & 8 & 10 & 5.28 \\
\hline A66 & 1996 & 20.5 & M & 14 & 9 & 6.65 & A86 & 2006 & 11.5 & $\mathrm{U}$ & 18 & 14 & 5.65 \\
\hline 177 & 1997 & 20.6 & M & 29 & 23 & 6.35 & A85 & 2005 & 12.5 & $\mathrm{U}$ & 9 & 6 & 4.84 \\
\hline A61 & 1994 & 23.5 & M & 19 & 9 & 6.81 & A79 & 2004 & 12.5 & $\mathrm{U}$ & 13 & 13 & 5.67 \\
\hline A60 & 1992 & 25.5 & M & 19 & 14 & 6.80 & A84 & 2005 & 12.6 & $\mathrm{U}$ & 17 & 12 & 5.60 \\
\hline G39 & 1986 & 31.5 & $\mathrm{M}$ & 8 & 4 & 6.51 & C26 & 2004 & 13.5 & $\mathrm{U}$ & 7 & 10 & 5.96 \\
\hline G32 & 1982 & 35.5 & $\mathrm{M}$ & 19 & 15 & 6.76 & I106 & 2004 & 13.5 & $\mathrm{U}$ & 22 & 15 & 5.96 \\
\hline A37 & 1977 & 37.5 & $\mathrm{M}$ & 11 & 10 & 6.87 & G73 & 2004 & 13.5 & $\mathrm{U}$ & 6 & 8 & 6.06 \\
\hline A38 & 1971 & 44.5 & $\mathrm{M}$ & 15 & 9 & 7.45 & I107 & 2004 & 13.5 & $\mathrm{U}$ & 24 & 14 & 4.93 \\
\hline G114 & 2017 & 0.5 & U & 12 & 13 & 2.90 & I102 & 2003 & 14.5 & $\mathrm{U}$ & 17 & 16 & 5.89 \\
\hline I153 & 2016 & 0.6 & $\mathrm{U}$ & 9 & 11 & 2.42 & I104 & 2002 & 15.5 & $\mathrm{U}$ & 11 & 9 & 5.69 \\
\hline I154 & 2016 & 1.5 & $\mathrm{U}$ & 16 & 12 & 3.45 & I98 & 2002 & 15.5 & $\mathrm{U}$ & 25 & 15 & 6.37 \\
\hline A113 & 2016 & 1.5 & $\mathrm{U}$ & 19 & 15 & 3.92 & A75 & 2002 & 15.6 & $\mathrm{U}$ & 16 & 16 & 5.82 \\
\hline $\mathrm{I} 146$ & 2014 & 3.5 & $\mathrm{U}$ & 5 & 7 & 4.08 & G69 & 2001 & 16.5 & $\mathrm{U}$ & 15 & 14 & 5.63 \\
\hline A109 & 2014 & 3.5 & $\mathrm{U}$ & 17 & 14 & 4.87 & G63 & 1999 & 18.5 & $\mathrm{U}$ & 3 & 4 & 5.79 \\
\hline G108 & 2014 & 3.5 & $\mathrm{U}$ & 7 & 9 & 4.26 & A72 & 1999 & 18.6 & $\mathrm{U}$ & 17 & 16 & 5.65 \\
\hline G107 & 2014 & 3.5 & $\mathrm{U}$ & 6 & 8 & 4.00 & $\mathrm{C} 23$ & 1998 & 19.5 & $\mathrm{U}$ & 13 & 11 & 6.02 \\
\hline
\end{tabular}

The change point model was fit to the length data for 22 females and 9 males over 20 yr of age (20.5$60.5 \mathrm{yr}$ for females and 20.5-44.5 yr for males; Fig. 3, Table 1) and estimated a likely change point between 40 and $41 \mathrm{yr}$ of age (95\% probability interval $[\mathrm{PI}]=36-44 \mathrm{yr}$ ). For whales younger than the change point, the average total length for females was $5.85 \mathrm{~m}$ $(95 \% \mathrm{PI}=5.74-5.96 \mathrm{~m})$ and for males $6.70 \mathrm{~m}(95 \% \mathrm{PI}$ $=6.56-6.85 \mathrm{~m}$ ), increasing by an estimated step magnitude of $0.44 \mathrm{~m}(95 \% \mathrm{PI}=0.25-0.62 \mathrm{~m})$ after the change point to average sizes of $6.28 \mathrm{~m}(95 \% \mathrm{PI}=$ $6.07-6.44 \mathrm{~m})$ and $7.14 \mathrm{~m}(95 \% \mathrm{PI}=6.91-7.35 \mathrm{~m})$, respectively. The model selection procedure estimated a high probability ( $p=0.99$ ) of selecting the change point model compared to the base model with no change in the sex-specific average lengths. This was supported by the residual standard deviation, which was lower around the change point model ( 0.21 vs. $0.29)$.

\section{DISCUSSION}

These analyses provide strong support for a change in the adult length of NRKWs that grew in recent decades compared to older whales that are still alive. 


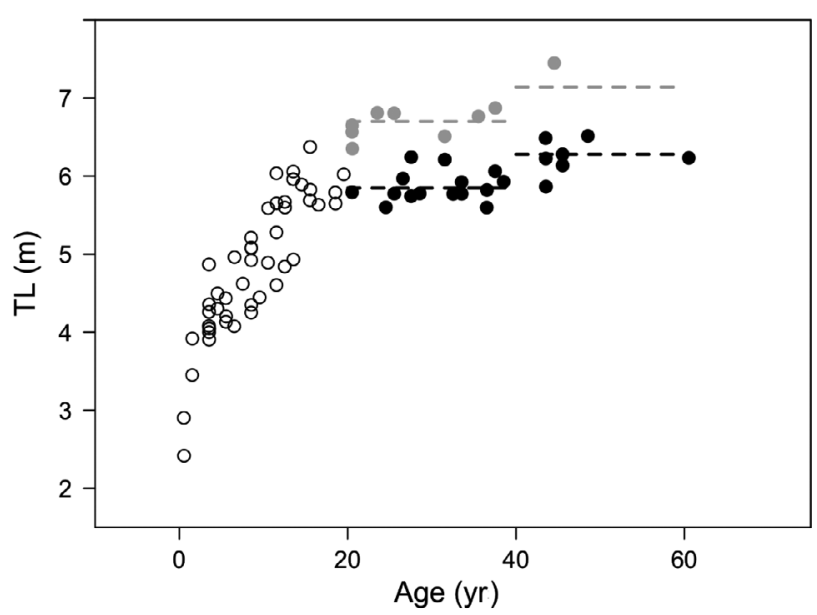

Fig. 3. Plot of total length (TL) against known age for 78 individual northern resident killer whales ( 22 females, black circles; 9 males, gray circles; 47 unknown sex and/or $<20$ yr of age, open circles). Also plotted are the medians of the posterior distributions for the estimated average sizes of both males and females before and after a change point estimated at 40 to $41 \mathrm{yr}$ of age by a Bayesian model fit to whales $>20 \mathrm{yr}$ of age

Specifically, adult whales that are 20 to $40 \mathrm{yr}$ old have significantly shorter body lengths than those $>40 \mathrm{yr}$ of age, which are typically $\sim 0.44 \mathrm{~m}$ longer. This pattern is driven primarily by the larger sample size of adult females but is consistent with the relatively large size of the single adult male over $40 \mathrm{yr}$ old in this data set. These data suggest that these younger adults experienced relatively constrained growth during their maturing years $(0-15 \mathrm{yr}$ of age for females and 0-20 yr for males; Fearnbach et al. 2011), which align with notable declines in Chinook salmon returns in the 1990s (Ford et al. 2010). The growth period of younger adults also coincides with declines in the size and proportional abundance of older Chinook salmon in more recent decades (Ohlberger et al. 2018), particularly the older age classes $(>2 \mathrm{yr})$ that are targeted by resident killer whales (Ford \& Ellis 2006).

The reduced adult size of NRKWs $<40 \mathrm{yr}$ of age is similar to that found for SRKWs measured in 2008, when adult whales $<30 \mathrm{yr}$ of age were shorter on average than older adults (Fearnbach et al. 2011). These changes were documented at different ages (10 yr apart) for the 2 populations, which suggests this is unlikely to reflect continued somatic growth through life (see Fearnbach et al. 2011), which is further supported by evidence of asymptotic growth in captive killer whales (Williams et al. 2011). Rather, these shorter NRKWs were actually growing at the same time period as the shorter SRKWs, as the 2 sets of measurement data were collected $10 \mathrm{yr}$ apart. This supports the hypothesis of correlated food limitation in both NRKWs and SRKWs and highlights the significant long-term effects of nutritional stress in salmoneating killer whales in the coastal eastern North Pacific. These photogrammetry measurements of free-ranging killer whales demonstrate that the aforementioned effects are not only acutely lethal (Ford et al. 2010) but also impact a larger number of individuals in the population. Non-lethal effects on condition and growth may help explain recent evidence of low reproductive success (Wasser et al. 2017) that-at least for the smaller SRKW population - is constraining recovery.

Acknowledgements. Hexacopter flights were authorized by Transport Canada (SFOC 9723488, 10854645, 11939499, 13026742), with whale overflights authorized by Fisheries and Oceans Canada (SARA license 2014-06 SARA-327). Funding for field efforts and analysis was provided by the SeaWorld Busch Gardens Conservation Fund, the National Fish and Wildlife Foundation Killer Whale Research and Conservation Program, NOAA Office of Marine and Aviation Operations (OMAO), and NOAA/NMFS Office of Science and Technology. We are grateful to Carla Crossman for logistical support and Wayne Perryman, Don LeRoi, and the NOAA/OMAO Aircraft Operations Center for unmanned aircraft support.

\section{LITERATURE CITED}

Carlin BP, Chib S (1995) Bayesian model choice via Markov chain Monte Carlo. J R Stat Soc Series B Stat Methodol 57:473-484

Carlin BP, Gelfand AE, Smith AFM (1992) Hierarchical Bayesian analysis of changepoint problems. J Appl Stat 41:389-405

Dawson SM, Bowman MH, Leunissen E, Sirguey P (2017) Inexpensive aerial photogrammetry for studies of whales and large marine animals. Front Mar Sci 4:366

* Durban JW, Fearnbach H, Barrett-Lennard LG, Perryman WL, Leroi DJ (2015) Photogrammetry of killer whales using a small hexacopter launched at sea. J Unmanned Veh Syst 3:131-135

Fearnbach H, Durban JW, Ellifrit DK, Balcomb KC III (2011) Size and long-term growth trends of Endangered fish-eating killer whales. Endang Species Res 13: 173-180

Fearnbach H, Durban JW, Ellifrit DK, Balcomb KC (2018) Using aerial photogrammetry to detect changes in body condition of endangered southern resident killer whales. Endang Species Res 35:175-180

Fisheries and Oceans Canada (2008) Recovery strategy for the northern and southern resident killer whales (Orcinus orca) in Canada. Species at Risk Act Recovery Strategy Series, Ottawa, Canada. www.sararegistry.gc.ca/virtual_ sara/files/plans/Rs-ResidentKillerWhale-v00-2018AugEng.pdf

F Ford JKB, Ellis GM (2006) Selective foraging by fish-eating killer whales Orcinus orca in British Columbia. Mar Ecol Prog Ser 316:185-199 
Ford JKB, Ellis GM, Olesiuk PF, Balcomb KC (2010) Linking killer whale survival and prey abundance: food limitation in the oceans' apex predator. Biol Lett 6:139-142

Hilborn R, Cox SP, Gulland FMD, Hankin DG, Hobbs NT, Schindler DE, Trites AW(2012) The effects of salmon fisheries on southern resident killer whales: final report of the Independent Science Panel. Prepared with the assistance of DR Marmorek and AW Hall, ESSA Technologies, Vancouver. National Marine Fisheries Service, Seattle, WA, and Fisheries and Oceans Canada, Vancouver

Lunn DJ, Thomas A, Best N, Spiegelhalter D (2000) WinBUGS -a Bayesian modelling framework: concepts, structure, and extensibility. Stat Comput 10:325-337

National Marine Fisheries Service (2008) Recovery plan for southern resident killer whales (Orcinus orca). National Marine Fisheries Service, Northwest Region, Seattle, WA. www.nmfs.noaa.gov/pr/pdfs/recovery/whale_killer.pdf

Ohlberger J, Ward EJ, Schindler DE, Lewis B (2018) Demographic changes in Chinook salmon across the northeast Pacific Ocean. Fish Fish 19:533-546

Editorial responsibility: Ana Cañadas, Durham, NC, USA
Olesiuk PF, Bigg MA, Ellis GM (1990) Life history and population dynamics of resident killer whales (Orcinus orca) in the coastal waters of British Columbia and Washington state. Rep Int Whal Comm Spec Issue 12:209-243

Towers JR, Ellis GM, Ford JKB (2015) Photo-identification catalogue and status of the northern resident killer whale population in 2014. Can Tech Rep Fish Aquat Sci 3139

*Ward EJ, Holmes EE, Balcomb KC (2009) Quantifying the effects of prey abundance on killer whale reproduction. J Appl Ecol 46:632-640

*Wasser SK, Lundin JI, Ayres K, Seely E and others (2017) Population growth is limited by nutritional impacts on pregnancy success in endangered southern resident killer whales (Orcinus orca). PLOS ONE 12: e0179824

* Williams R, Krkošek M, Ashe E, Branch TA and others (2011) Competing conservation objectives for predators and prey: estimating killer whale prey requirements for Chinook salmon. PLOS ONE 6:e26738

Submitted: May 24, 2019; Accepted: September 9, 2019 Proofs received from author(s): November 6, 2019 